Aesthetics in

Dermatology and

Aesthet Dermatol Surg 2017;1:2-7

Surgery

DOI: $10.1159 / 000454913$

Received: October 5, 2016

Accepted: December 5, 2016

Published online: February 10, 2017

\title{
Q-Switched Laser Treatment for Freckles in Individuals with Skin Type V
}

\author{
Ganesh S. Pai Anusha H. Pai \\ Derma-Care, Skin and Cosmetology Centre, Mangalore, India
}

\section{Keywords}

Freckles · Skin type V - Q-switched Nd:YAG laser .

Hyperpigmentation · Hypopigmentation · Sunscreen

\section{Abstract}

Freckles are usually thought of as small, poorly marginated, well-circumscribed, pale brown macules present on sun-exposed skin areas in fair-complexioned individuals. However, freckles also occur in patients who have skin types IV and V, and there is a risk of prolonged depigmentation after treatment with a Q-switched laser emitting wavelengths of 532 $\mathrm{nm}$. Unlike in fair-complexioned patients with light eyes and auburn hair who respond well but relapse in a matter of weeks, patients with skin type $V$ show a permanent and satisfactory response to laser therapy. However, lower energies have to be used to prevent permanent hypopigmentation, which stands out in patients with skin of color. It is advisable to perform test spots on freckles before treating the entire face. After treatment, freckles can become of an ash white color. Test spots can be evaluated after 6 weeks. Sunscreen should be mandatory after the procedure. Additionally, freckles should be differentiated from lentigines by Wood lamp examination, where the superficial freckles get accentuated. Lentigines are treated using wavelengths of $1,064 \mathrm{~nm}$.

(c) 2017 S. Karger AG, Basel

\section{Introduction}

Freckles are commonly found in skin types I-IV and are uncommonly noted in skin type $\mathrm{V}$. They are seen as small, poorly marginated, pale brown macules on sunexposed skin areas. Often there is a genetic predisposition. Microscopically, an increased amount of melanin is produced in the melanocytes. Sun exposure results in the aggravation of freckles, and there is an increase in density and color in the summer months. Freckles should be distinguished from lentigines. Lentigines are well-circumscribed, small, brown spots which appear both on sun-exposed and nonexposed areas. They can be seen on mucus membranes as well as nail beds. Microscopically, they represent an increased number of melanocytes at the dermoepidermal junction. Freckles can be distinguished from lentigines by Wood lamp examination; the pigmentation of freckles is then accentuated [1].

Freckles are efficiently targeted with Q-switched $\mathrm{Nd}$ :YAG lasers emitting wavelengths of $532 \mathrm{~nm}$, whereas lentigines are more amenable to treatment with $\mathrm{Nd}: Y A G$ lasers at $1,064 \mathrm{~nm}$. The treatment usually ends with a highly satisfactory result, with the scabs falling off by the seventh day after treatment.

Q-switched Nd:YAG lasers are highly pigment selective targeting the endogenous melanin. The Q-switched

\section{KARGER}

(c) 2017 S. Karger AG, Basel

E-Mail karger@karger.com

www.karger.com/ads
Dr. Ganesh S. Pai, Medical Director

Derma-Care, Skin and Cosmetology Centre Trade Centre Building, Opposite Gold Finch Hotel

Bunts Hostel Road, Mangalore 575003 (India)

E-Mail gspai@derma-care.in 


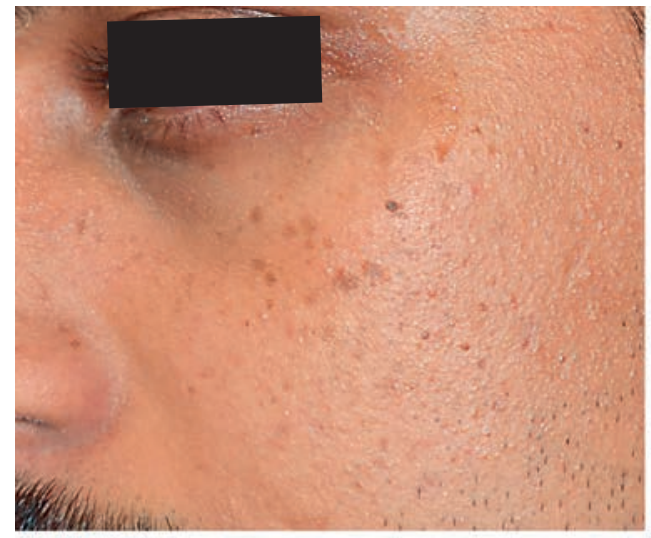

Before

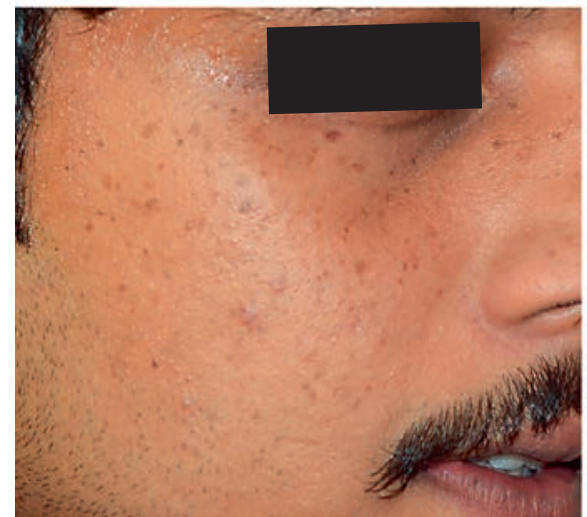

Before

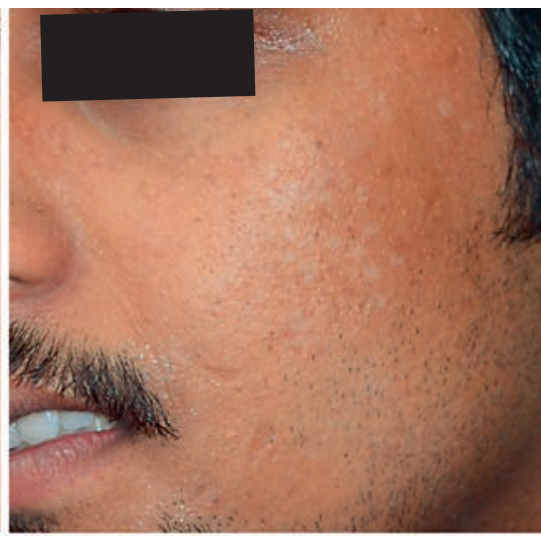

After

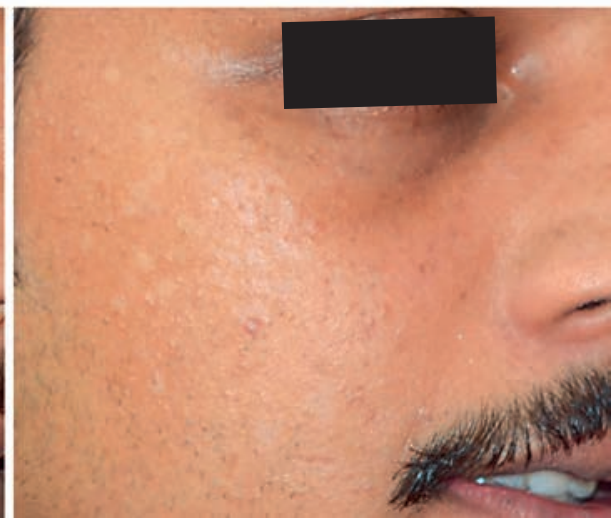

After laser treatment.

device acts as an extremely high-speed shutter. It allows the Nd:YAG rod to store a large amount of energy and permits a single, high-energy, high-speed pulse to exit the cavity. It deposits energy in pulses in the range of nanoseconds. The beam can be made uniform or fractionalized. A fractional hand piece reduces the time the laser beam touches the skin and minimizes the damage in normal cells with a quick recovery time, as the laser's energy is deposited on the skin surface in an interval pattern with islands of unaffected skin [2]. Heat-induced steam cavities in the melanosomes cause the scattering of visible light, resulting in an ash white color at the site of treatment.

\section{Methods}

Forty-three patients with Fitzpatrick skin type V underwent Q-switched Nd:YAG laser treatment (at wavelengths of $532 \mathrm{~nm}$ ) for their freckles. All patients were instructed to use a sunscreen with SPF $\geq 50$ for 2 weeks before the laser treatment and avoid outdoor activities. All procedures were done as outpatient proce- dures. Informed consent was obtained from the patients before the laser treatment. Photographs were taken prior to treatment. The area to be treated was numbed with topical anesthesia using a combination of prilocaine and lidocaine cream. The eyes of the patients were protected with goggles. In all cases, test spots were done and the results were checked after 1 month to determine the parameters before performing the laser treatment on the entire area.

The laser machine used was an Alma Harmony Pro XL at 532 $\mathrm{nm}$, with an aperture of $3 \mathrm{~mm}$ and a frequency of $4 \mathrm{~Hz}$. A constant energy of $400 \mathrm{~mJ}$ was used. The end point was immediate ash white color. Ice packs were applied on the treated areas to reduce erythema and edema (see www.karger.com/doi/10.1159/000454913 for online suppl. video).

After the procedure, mupirocin $1 \%$ ointment was given to the patients to be applied twice daily on the treated areas till the scabs fell off. All patients were asked to avoid unnecessary sun exposure for 1 week after the laser treatment. Another set of photographs were taken directly after the laser treatment as well as on the second visit. Combinations containing kojic acid, arbutin, and azelaic acid were used 1 week after the laser treatment once the scabs had fallen off along with daytime use of sunscreen. The final results were analyzed after 1 month. All photographs were compared to check the treated areas before and after laser treatment. 


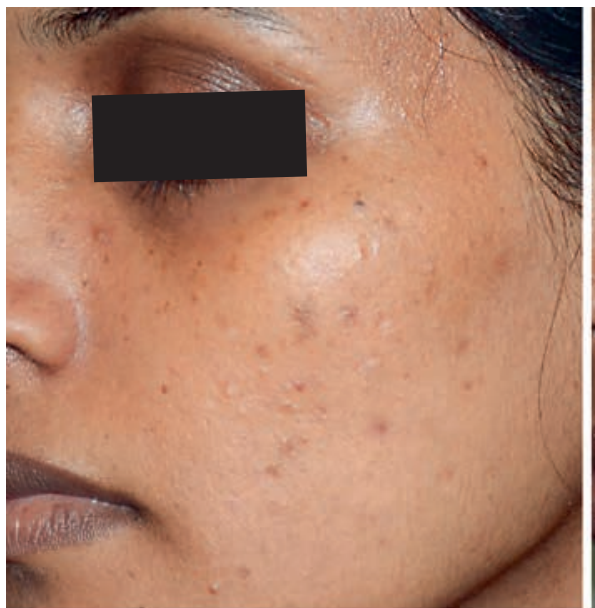

Before

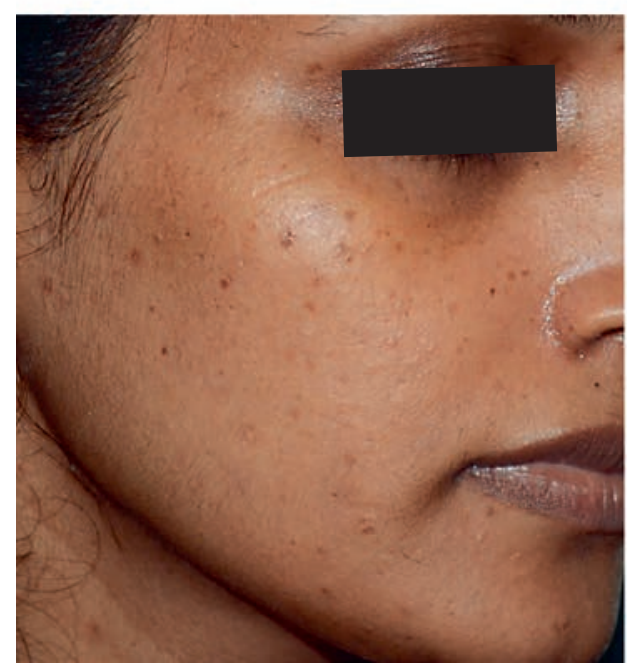

Before

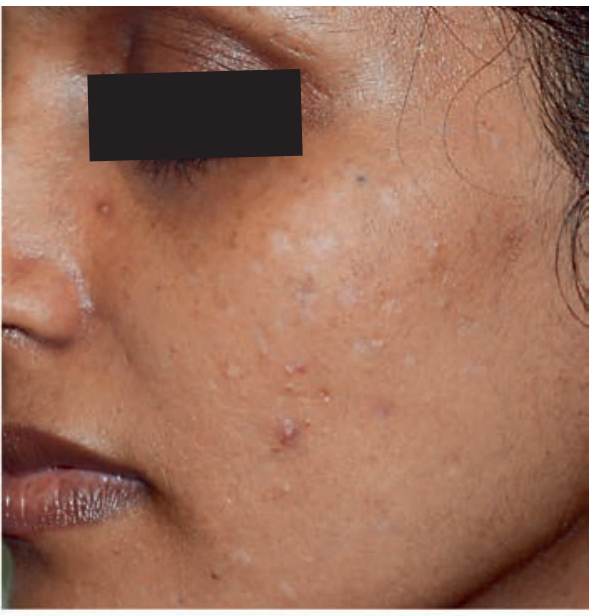

After

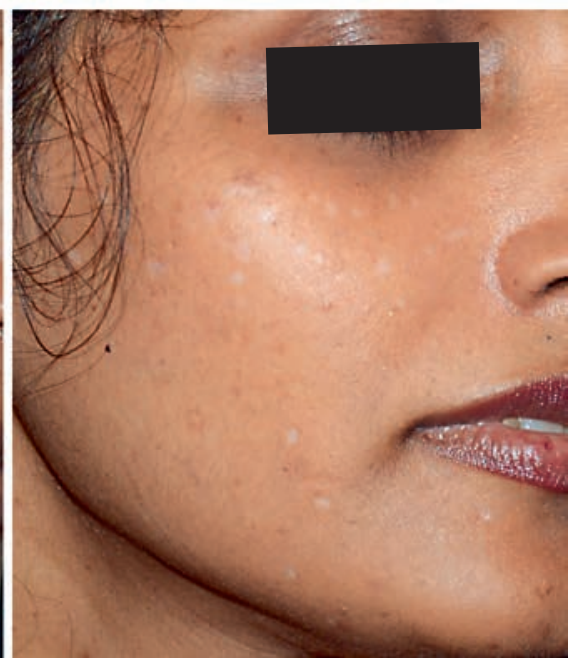

After
Fig. 2. Examples
laser treatment.

\section{Results}

Immediately after the laser treatment, all patients had erythema and edema at the treated site, which decreased after some time. Crusting was observed on day 2 and scabs from day 3 onwards. Out of 43 patients, 23 showed significant improvement after the laser treatment. Seven patients developed hyperpigmentation at the treated site. Thirteen patients developed prolonged hypopigmentation.

\section{Discussion}

Wavelengths of $1,064 / 532 \mathrm{~nm}$ are best suited to a dark pigment chromophore. Green laser light is particularly effective on brown spots and freckles. The reason green light works so well at removing brown spots is because melanin pigment is designed to block light with short wavelengths, namely ultraviolet light, which is shorter than any visible color of light. So, light with shorter wavelengths is more strongly picked up by the melanin in the freckles; thus, low energies of green light are used to treat brown spots. The resulting ash white color in the target areas indicates that the energy has been fully absorbed by the freckles and that the ablation has been complete [3].

The results of laser treatment of freckles are generally permanent. However, due to the relationship between chronic ultraviolet light exposure and the development of freckles, all patients were told to expect more lesions over a period of 1 year or more, especially in patients inconsistent with the use of sunscreen with SPF $\geq 50$. 


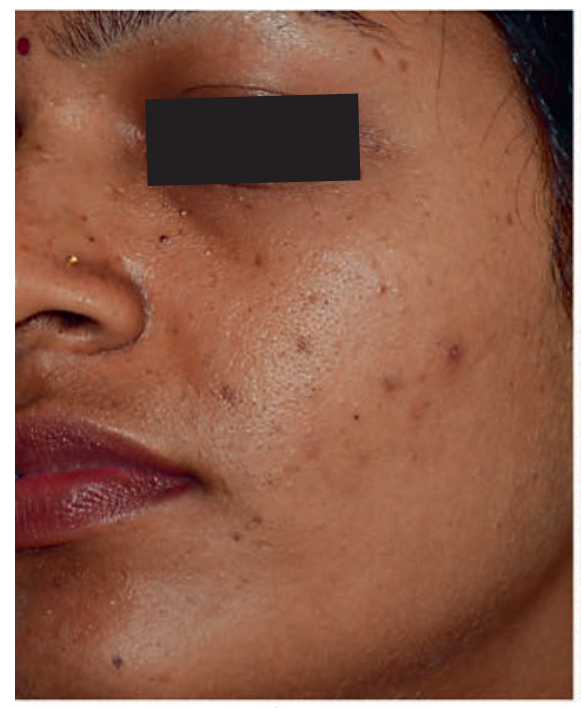

Before

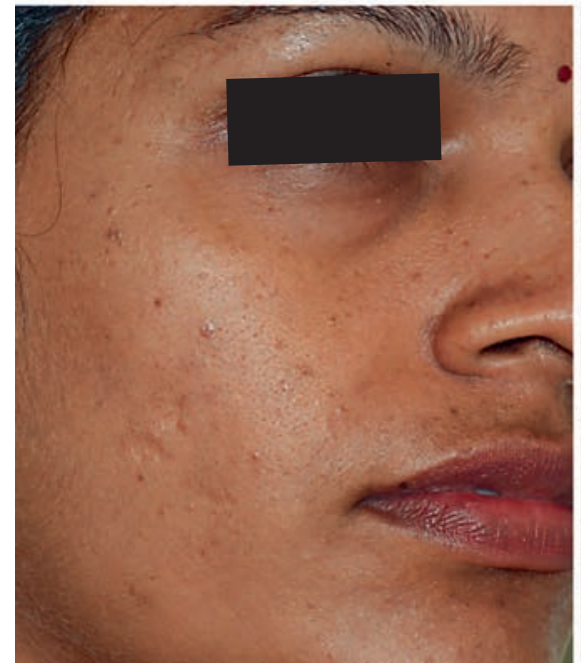

Before

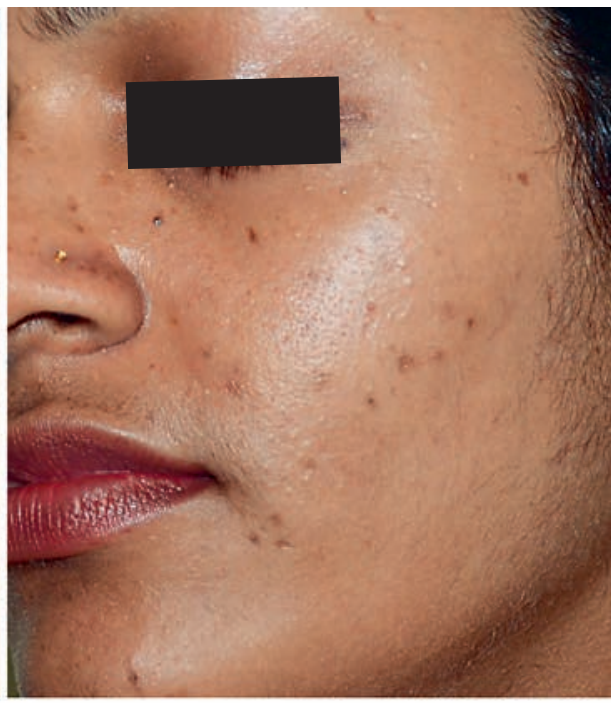

After

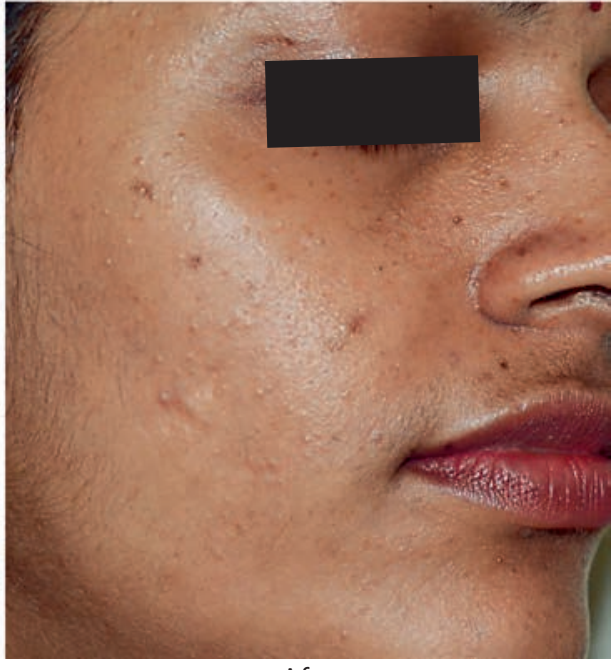

After ter laser treatment.
In our clinical experience, we treated a total of $43 \mathrm{pa}-$ tients of skin type $\mathrm{V}$ with freckles. We infer from treating those patients that the results are inconsistent and unpredictable in contrast to those of patients with lighter skin types. Twenty-three patients (53.48\%) had satisfactory results with a complete disappearance of freckles. Thirteen patients $(30.23 \%)$ had prolonged hypopigmentation (Fig. 1, 2), while 7 patients (16.27\%) developed persistent hyperpigmentation (Fig. 3, 4). Postinflammatory hyperpigmentation improved with the judicious use of broadspectrum sunscreen with SPF $\geq 50$ and with topical skinlightening agents like kojic acid, arbutin, and azelaic acid. Permanent hyperpigmentation did not occur in any pa- 


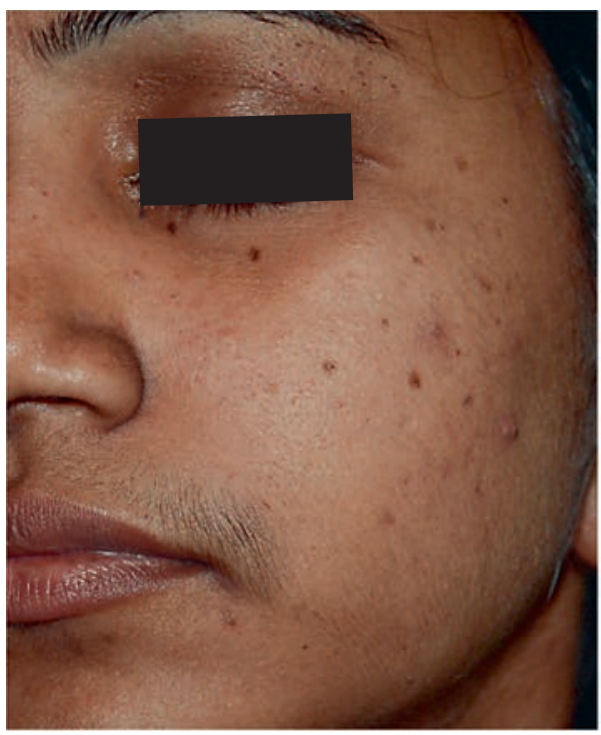

Before

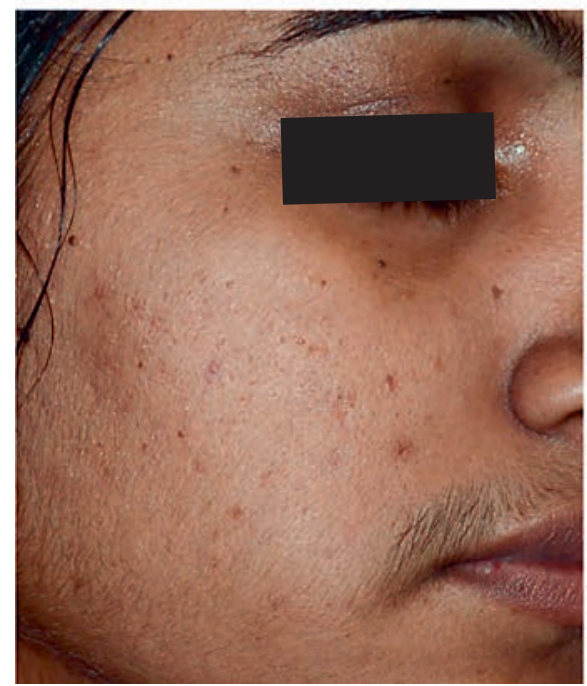

Before

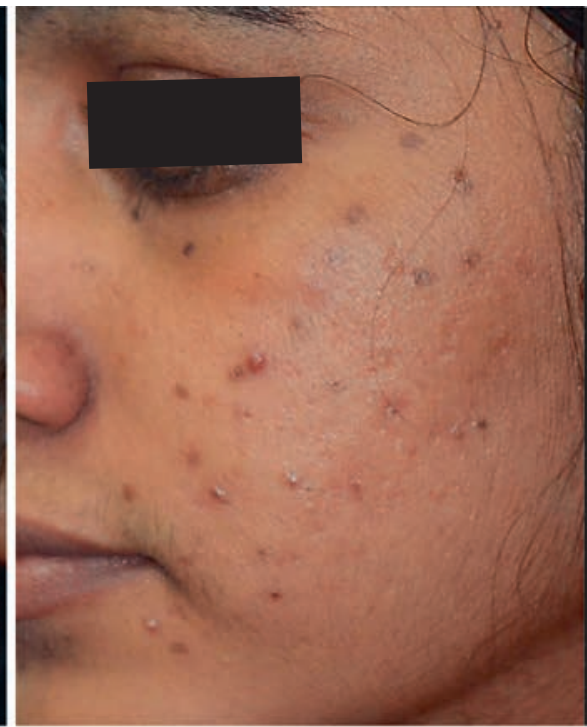

After

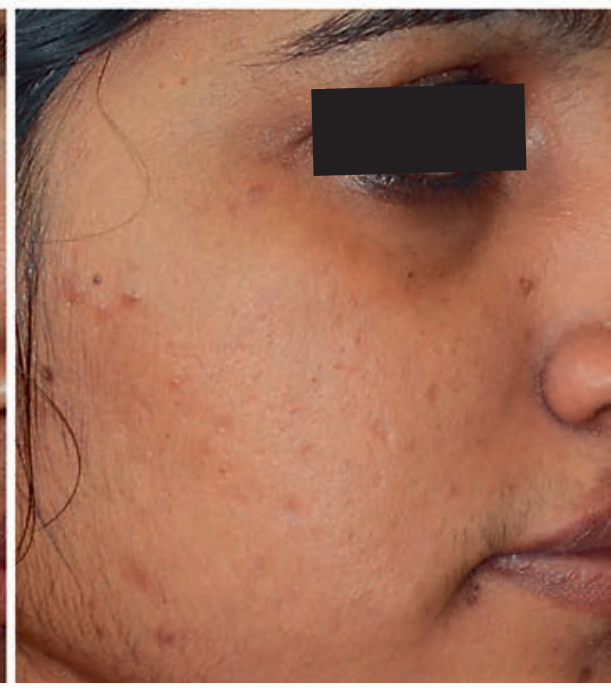

After ter laser treatment.

\section{Statement of Ethics}

Informed consent was obtained from the patients before laser treatment.

\section{Conflict of Interest Statement}

The authors have no conflicts of interest to disclose. treatment perhaps hinders normal pigment restoration in the freckled skin leading to prolonged hypopigmentation. Patients with skin of color must be counseled on resultant hyperpigmentation or hypopigmentation of the lasered spots for a prolonged period of time. 


\section{References}

1 Pai GS, Pai AH: Complications in Q-switched laser; in Pai GS (ed): Complications in Cosmetic Dermatology Crafting Cures, ed 1. New Delhi, Jaypee, 2016, pp 3-19.

2 Schmults CD, Wheeland RG: Pigmented lesions and tattoos; in Goldberg D, Dover JS, Alam M (eds): Procedures in Cosmetic Dermatology Series: Lasers and Lights, ed 2. Philadelphia, Saunders, 2006, pp 41-66.
Lask GP, Glassberg E: Neodymium:yttriumaluminium-garnet laser for the treatment of benign cutaneous lesions. Clin Dermatol 1995; 13:81-86.

4 Vejjabhinanta V, Elsaie ML, Patel SS, et al: Comparison of short-pulsed and long-pulsed $532 \mathrm{~nm}$ lasers in the removal of freckles. Lasers Med Sci 2010;25:901-906. 